\title{
Quando a história se faz apelo...ou por quê as universidades não estão usando sua inteligência para repensar-se?
}

Denise Leite y Carlos Alexandre Netto

\begin{abstract}
Resumo
Os estudantes reformadores de 1918 auto-exerceram o direito de pensar sobre si mesmos e repensar a sua universidade. Cem anos após, relembramos os feitos e nos perguntamos, onde está a periodicidade das reformas quando, no século XXI, as universidades são acusadas de não usar suas inteligências para pensar sobre si mesmas. Neste artigo descrevemos três acontecimentos interligados, um ciclo de conferências, Case local, um seminário, Case nacional, um encontro de redes, Case regional. Tais atividades foram preparatórias às comemorações do Centenário da Reforma de Córdoba e à Conferência CRES 2018. Mobilizaram um importante contingente de pessoas e convocaram ao debate frente aos apelos da história. As atividades interligadas produziram resultados. Ao final, discutimos o alcance reformista dessa mobilização de inteligências para repensar a universidade contemporânea e a do futuro.
\end{abstract}

\section{When history makes appeal ... or why universities are not using their intelligence to rethink themselves?}

\footnotetext{
Abstract

The reforming students of 1918 self-exercised the right to think about themselves and rethink their university. A hundred years later, we remember the facts and ask ourselves, where is the periodicity of reforms when, in the 21st century, universities are accused of not using their brains to think about themselves. In this article we describe three interrelated events, one conference cycle, local case, one seminar, national case, one networking meeting, regional case. These activities were preparatory to the celebrations of the Centenary of the Reform of Cordoba and to the CRES 2018 Conference. They mobilized an important contingent of people and called for the debate in front of the appeals of history. Interconnected activities produced results. In the end, we discussed
}

Palavras-chave:

Reforma de Córdoba, universidade, CRES 2018, estudantes universitários, inteligência universitária.

Keywords:

Cordoba Reform, university, CRES 2018, university students, university intelligence. 
the reformist reach of this mobilization of intelligences to rethink the contemporary university and that of the future.

\section{¿Cuándo la historia se hace apelación ... o por qué las universidades no están usando su inteligencia para repensarse?}

\section{Resumen}

\section{Palabras clave:}

Reforma de Córdoba, universidad, CRES 2018 estudiante universitario, inteligencia universitaria.
Los estudiantes reformadores de 1918 autoejercieron el derecho de pensar sobre sí mismos y repensar su universidad. Cien años después, recordamos los hechos y nos preguntamos, donde está la periodicidad de las reformas cuando, en el siglo XXI, las universidades son acusadas de no usar sus inteligencias para pensar sobre sí mismas. En este artículo describimos tres acontecimientos interconectados, un ciclo de conferencias, Case local, un seminario, Case nacional, un encuentro de redes, Case regional. Tales actividades fueron preparatorias a las conmemoraciones del Centenario de la Reforma de Córdoba ya la Conferencia CRES 2018. Movilizaron un importante contingente de personas y convocaron al debate frente a los llamados de la historia. Las actividades interconectadas produjeron resultados. Al final, discutimos el alcance reformista de esa movilización de inteligencias para repensar la universidad contemporánea y la del futuro.

Acadêmicos de diferentes áreas de conhecimento, tanto quanto historiadores, são unânimes em afirmar que os estudantes reformadores de 1918 auto-exerceram o direito de pensar sobre si mesmos e repensar a sua universidade, no contexto político e social de uma época em que extraordinários acontecimentos estavam a eclodir. A Universidade de Córdoba, em que pese o contexto de transformações a ocorrerem naquele início de século XX, estava culturalmente submetida ao pensamento religioso e, ainda que guardasse uma feição europeia, se mantinha dominada pelos dogmas e pela visão eurocentrista de mundo. Contudo, os estudantes, munidos da ousadia da juventude, romperam com esses e outros 'grilhões' que os atormentavam e levantando sua voz, desde o interior da Argentina, elevaram-na ao continente latino-americano. Os estudantes de um século atrás, ao dar-se conta das mazelas que os oprimiam como cidadãos e como estudantes, dentro e fora das salas de aula, lançaram o grito que se fez história e apelo aos "homens livres da América (SudAmerica)" (Barros et al, 1918).

A admirável coragem dos jovens insurgentes, os revolucionários consequentes, no dizer de Darcy Ribeiro (1982; 1983), colocou-se na história com implicações diretas para a instituição dos princípios da autonomia e da liberdade acadêmica, para a construção de um modelo de universidade latino-americana e caribenha, crítica e democrática. As ações reformistas vieram a estabelecer o apelo ao corolário co-governo na universidade com democracia na sociedade. Os estudantes conclamaram a periodicidade revolucionária, para que as universidades não esmorecessem na luta contra a opressão e o obscurantismo. O movimento não se esgotaria após atendidas as pautas reformistas. Quis a história que tais pautas sofressem transformações e metamorfoses, dando origem a tantas outras que nos dias atuais sufocam as universidades e os seus públicos, os jovens que nelas querem estudar e cujas condições sociais não lhes permitem ingresso.

Cem anos após, relembramos os feitos e nos perguntamos, onde está a periodicidade das reformas quando, no século XXI, somos acusados -estudantes, docentes, pesquisadores, técnicos-, a comunidade acadêmica, de continuarmos a rejeitar o pensamento sobre nós mesmos e nossas atividades? Na opinião de Mulgan (2018), expressa no Times Higher Education, as universidades são grandes centros de inteligência, mas, 
não são centros de inteligência sobre si próprias, ainda que sejam centros de excelência em pesquisa de inúmeros temas relevantes. Acusa-nos Mulgan de fazermos reduzida atividade sistemática de pesquisa e desenvolvimento de nossas próprias atividades. Acrescentaríamos, reduzida atividade de revisão de nossa missão, princípios e valores.

Neste artigo vamos argumentar com exemplos, para contestar a opinião do editorialista do THE mostrando que, sim, as universidades se repensam, seja através da avaliação com auto-análise que realizam periodicamente, seja construindo iniciativas e atividades inovadoras tais como aquelas relatadas neste artigo. Com este objetivo, descrevemos três acontecimentos interligados intitulados a. Conferências CRES; b. Seminário de Brasília; c. Encontro de Redes Universitárias. Todas as atividades foram realizadas em tempo definido e anterior, preparatório, às comemorações do Centenário da Reforma de Córdoba. Foram preparatórias à CRES, Conferência Regional de Educação Superior. Foram atividades para repensar a universidade contemporânea e a do futuro. Mobilizaram um importante contingente de pessoas, instigaram o debate e fustigaram ideias e ideais.

Nas secções seguintes, apresentamos os cases e os produtos. Ao final, discutimos o alcance reformista da mobilização de inteligências para que a universidade venha pensar a si mesma.

\section{Os cases local, nacional e regional}

\section{Case 1 - Local}

Em 11 de julho 2017 o Reitor da Ufrgs, Prof. Rui Carlos Oppermann e a Vice-Reitora Profa. Jane Tutikian lideraram um grupo para discutir temáticas e princípios ordenadores propositivos com vistas à CRES 2018. O grupo foi formado por acadêmicos, pesquisadores, dentre eles, ex-reitores, pró-reitores, sindicalistas e estudantes. Celebrando o centenário do Movimento Reformista de Córdoba foi questionada a oportunidade -e a necessidade- de um novo manifesto. Considerando que as sociedades mudaram, as universidades evoluíram e os desafios do século 21 são diferentes daqueles da Córdoba de 1918. O grupo destacou que, hoje, uma das mais importantes lutas é pela manutenção da universidade pública, de qualidade, acessível a todos. Foi lembrado que a proposta da CRES, tem em vista internacionalizar as universidades com foco regional, o que significa uma nova utopia: definir, solidariamente entre as instituições, da América Latina e Caribe as diretrizes comuns para ações e projetos com vistas ao desenvolvimento da região (Netto, 2018).

Vários encontros realizados, entre os meses de julho e outubro, definiram os temas a serem discutidos com a comunidade acadêmica ampla, a saber: Relação de Universidade com sociedade; Igualdade, equidade e inclusão (gênero, diversidade, classe social); Privatização como um dos grandes pontos de análise, pois, conforme a OMC, Organização Mundial do Comércio, o ensino superior como bem social, não é para todos; Governança da universidade; Protagonismo estudantil; Papel da juventude; Governabilidade. Primórdios da autonomia para chegar à governabilidade; Participação e responsabilidade no governo da universidade; Sustentabilidade; Responsabilidade social; Direito à educação; Diversidade cultural e interculturalidade; Ciência como pertinência social em benefício do ser humano; Produção e uso do conhecimento enraizados no espaço social e político latino-americano. A metodologia pensada e executada era simples. Por iniciativa do reitorado, reuniu-se o grupo inicial de "pensadores", revisaram-se os postulados de Córdoba, as reuniões anteriores da CRES e a Conferência Mundial Unesco de 1998. Definidos os temas, os grandes problemas 
atuais da universidade pública, escolheu-se um curador, prof. Carlos Alexandre Netto, para organizar um ciclo de conferências cujo objetivo seria preparar a comunidade para a participação consciente na CRES 2018. A curadoria providenciou os locais e datas das palestras e dividiu tarefas com os "pensadores" e setores especializados da universidade. Criou um logo e organizou um site intitulado Conferências Ufrgs 2017. As conferências foram filmadas em vídeo e disponibilizadas em tempo real no Youtube e, posteriormente, hospedadas no repositório digital da Ufrgs. Foram precedidas de entrevistas com os palestrantes divulgadas em vídeo, online no site e na rádio da universidade. Toda a universidade foi convidada a participar. Foi aberta uma modalidade de presença registrada para aqueles que quisessem ganhar créditos acadêmicos. Os principais produtos, as conferências e mesa redonda, atraíram um público considerável ao longo dos vários meses de sua realização e foram assim constituídas:

» Conferência 1 - Papel estratégico da educação superior no desenvolvimento sustentável da América Latina e do Caribe, apresentada por Rui Vicente Oppermmann, Reitor da UFRGS hospedada em: https://www.ufrgs.br/cres2018ufrgs/repositorio Rui Vicente Oppermmann

» Conferência 2 - A comunidade universitária e a educação superior na AL e C, apresentada por Eduardo Rolim, Professor Titular do Instituto de Química da UFRGS, Presidente do PROIFES Sindicato (Sindicato Docente), hospedada em: https://www.ufrgs.br/cres2018ufrgs/ repositorio, Eduardo Rolim

» Conferência 3 - A educação superior face aos desafios sociais na AL e C, apresentada por José Vicente Tavares dos Santos, Diretor do Instituto Latinoamericano de Estudos Avançados da UFRGS, hospedada em: https://www.ufrgs.br/cres2018ufrgs/repositorio, jose-vicentetavares-dos-santos

» Conferência 4 - Autonomia e democracia nas Universidades da $A L$ e $C$, apresentada por Wrana Pannizzi, Ex- Reitora da UFRGS, hospedada em: https://www.ufrgs.br/cres2018ufrgs/ repositorio, Wrana Panizzi

» Conferência 5 - Direito à educação superior na $A L$ e C, apresentada por Marília Morosini, Professora Titular da Faculdade de Educação da PUCRS; hospedada em: https://www.ufrgs. br/cres2018ufrgs/repositorio, Marília Morosini

» Conferência 6 - A pedagogia da Reforma de Córdoba e a integração regional na AL e Caribe, apresentada por Denise Leite, Docente Pesquisadora Programa Pós Graduação Educação, hospedada em: https://www.ufrgs.br/cres2018ufrgs/repositorio, Denise Leite

» Conferência 7 - A educação superior como parte do sistema educacional na AL e C, apresentada por Maria Beatriz Luce, Professora Titular da Faculdade de Educação da UFRGS, Ex-Reitora da UNIPAMPA, hospedada em: https://www.ufrgs.br/cres2018ufrgs/repositorio, Maria Beatriz Luce

» Conferência 8 - Integração acadêmica latinoamericana, apresentada por Hélgio Trindade, ExReitor da UFRGS e Ex-Reitor da UNILA, hospedada em: https://www.ufrgs.br/cres2018ufrgs/ repositorio, Hélgio Trindade

» Conferência 9 - Pós-graduação e ciência na AL, apresentada por Lívio Amaral, Professor Titular do Instituto de Física da UFRGS, ex-Diretor de Avaliação da CAPES, hospedada em:https://www.ufrgs.br/cres2018ufrgs/repositorio, Livio Amaral

» Conferência 10 - Educação superior, diversidade cultural e interculturalidade na $A L$ e $C$, apresentada por Sandra de Deus, Pró-Reitora de Extensão da UFRGS, hospedada em:https:// www.ufrgs.br/cres2018ufrgs/repositorio, Sandra de Deus

» Conferência 11 - O Movimento Estudantil na Universidade Brasileira, mesa-redonda apresentada por Edilson Nabarro (Servidor Técnico-Administrativo e dirigente da Coordenadoria de Ações Afirmativas da UFRGS), Ramaís de Castro Silveira, e Glauco Araújo, ambos Presidentes do Diretório Central de Estudantes da UFRGS, hospedada em: https://www.ufrgs. br/cres2018ufrgs/repositorio, Edilson Nabarro e outros

» Conferência 12 - Cem Anos da Reforma de Córdoba - Um Novo Manifesto? apresentada por Carlos Alexandre Netto, Ex-Reitor da UFRGS. hospedada em: https://www.ufrgs.br/ cres2018ufrgs/repositorio, Carlos Alexandre Netto 
Como resultado das conferências e da ampla discussão com a comunidade local foi elaborado um artigo pelo Curador do evento, prof. Dr. Carlos Alexandre Netto, com a coautoria de alguns conferencistas, intitulado "Repensando a educação superior na América Latina e Caribe: Princípios, missão e valores". O trabalho foi resultado da construção dialógica das conferências, das reflexões críticas havidas. Constitui uma resposta às questões locais e globais que afligem as instituições e os países tendo em vista o futuro da educação superior. O artigo foi publicado em um dos livros da Coleção CRES 2018. Em seus lineamentos gerais também foi utilizado como documento base da reunião nacional de Brasília. Em abril de 2018 o ILEA, Instituto Latino-americano de Estudos Avançados fez o fechamento do tema com a comunidade em um Painel intitulado Atualidade da Reforma de Córdoba transmitido ao vivo pela TV Ufrgs e depositado no Canal Youtube.

\section{Fontes:}

» Netto, Carlos Alexandre (Org), Leite, D., Tutikian, J.F., Tavares dos Santos, J. V., Luce, M. B., Morosini, M., De Deus, S., Panizzi, W. Repensando a educação superior na América Latina e Caribe: Princípios, missão e valores. In: Guajardo, Pedro Henríquez (Coord). El papel estratégico de la educación superior em el desarrollo sostenible de América Latina y el Caribe. Caracas, Ve. Unesco/Iesalc y Córdoba, Ar. Editorial Universidad Nacional de Córdoba, 2018. Em: http://www.cres2018.org/uploads/DesarrolloSostenible\%204junio\%20diagramado.pdf

» ILEA Ufrgs Adufrgs sindical. Atualidade da Reforma Universitária de Córdoba. Ciclo de debates. A Universidade do Futuro. Porto Alegre, Ilea, 12 abril 2018. Em: www.adufrgs.org. br/noticias/53449/

\section{Case 2 - Nacional}

Seminário de Brasília. Proposta da Educação Pública Superior do Brasil à CRES-2018: Andifes, Abruem e Conif.

Em 24 de abril reuniram-se em Brasília, capital federal do Brasil, integrantes da Andifes, Associação Nacional de Diretores das Instituições Federais de Educação Superior, Abruem, Associação Brasileira de Reitores de Universidades Estaduais e Municipais e o Conif, Conselho Nacional das Instituições da Rede Federal de Educação Profissional Científica e Tecnológica. Presentes Emmanuel Zagury Tourinho - Andifes; Aldo Nelson Bona - Abruem; Roberto Gil Rodrigues Almeida, Conif. Foram convidados especiais, Waldo Albarracín Sánchez, AUGM, Uruguay, Pedro Guajardo, Iesalc-Unesco, Venezuela; Francisco Tamarit, coordenador CRES-2018, Argentina, e o grupo integrante do Conferências CRES Ufrgs mais participantes inscritos. O seminário incluiu a discussão do tema universidade pública como projeto de nação tendo como referente o movimento reformista de Córdoba e a proposta a ser enviada à CRES. Duas palestras precederam os debates. A primeira versou sobre o "Financiamento da educação superior pública no Brasil" e esteve a cargo do Prof. Dr. Nelson Cardoso Amaral, da Universidade Federal de Goiás (UFG) e a segunda teve como tema "A Educação e a Integração na América Latina", proferida pelo Embaixador (Itamaraty, Brasil) Samuel Guimarães. A metodologia do evento, além das palestras e discursos de abertura, incluiu a discussão dos participantes organizados em grupos de trabalho. Cada grupo dedicouse a estudar e discutir um dos sete eixos centrais da III CRES, a seguir enunciados: 1. O papel estratégico da educação superior no desenvolvimento sustentável da América Latina e do Caribe; 2. A educação superior como parte do sistema educativo na América Latina e no Caribe; 3. Educação superior, diversidade cultural e interculturalidade na América Latina e no Caribe; 4. Educação superior, internacionalização e integração regional da América Latina e do Caribe; 5. O papel da educação superior frente aos desafios sociais da América Latina e do Caribe; 6. A pesquisa científica e tecnológica e a inovação como motor do desenvolvimento humano, social e econômico da América 
Latina e do Caribe; 7. Os cem anos da Reforma Universitária de Córdoba, um Novo Manifesto. Como resultado das discussões, e produto deste Seminário, foi elaborada a Carta de Brasília, posteriormente enviada à coordenação da CRES, Argentina. O documento Carta de Brasília, inicia reafirmando a importância estratégica da educação superior pública e o papel das universidades para a formação profissional de qualidade e cidadã. Refere a expansão da educação superior privada e o crescimento da educação privada com fins de lucro, especialmente no Brasil podendo estender-se o fenômeno ã América Latina e Caribe. Tais instituições se transformaram em grandes empresas de mercado as quais operam também com recursos públicos, gerando preocupação pelo "fato de que esse sistema privado, com a forte presença de fundos de investimento, depende do financiamento público para auferir seus lucros". Continua o documento referindo que a educação superior é um bem público, um dever do Estado e não uma atividade comercial exercida com fins lucrativos. Nesse sentido, a Carta afirma que "é essencial que o estado assuma o financiamento público da educação superior integrado à educação básica, segundo os princípios e conceitos definidos em Cartagena (II CRES). Subjacente a essa proposição está dito que o ensino também deve ser gratuito". Outros temas são trazidos ao documento tais como acesso dos jovens à educação superior pública de qualidade, sua permanência, políticas de assistência estudantil; novas e inovadoras metodologias de ensino-aprendizagem; integração regional no plano acadêmico; responsabilidade social das universidades. Também consta a preocupação dos dirigentes universitários e participantes das instituições públicas com a internacionalização, a qual foi entendida como "oportunidades de formação e de pesquisa" a serem "promovidas dentro da perspectiva de uma internacionalização solidária, capaz de contribuir para a diminuição das assimetrias regionais existentes". Ao concluir, o documento retoma o papel das instituições que, ao produzir pesquisas, "possibilitem suas aplicações através de metodologias de pesquisa-ação"; ao desenvolver extensão universitária, favoreçam "a troca de saberes entre culturas diversas". Acrescenta ainda, que as "políticas de inovação e de pesquisa, aplicadas através da inovação, junto às empresas são essenciais para a geração de emprego e renda para a população". Explica que a "proposta é acrescentar ao debate vivências da educação superior onde, por ora, a realidade é marcada por confrontos e avanços significativos". Além disto, a Carta de Brasília, repetindo o manifesto de Córdoba e parte das discussões havidas em Porto Alegre, acrescentou em seu último parágrafo que a Pedagogia da Reforma de Córdoba se manifesta na busca da ciência com verdade, a extensão com dignidade e objetivo social, o ensino livre, com docentes que sejam "verdadeiros construtores de almas, criadores da verdade, da beleza e do bem" professando a educação como uma "longa obra de amor aos que aprendem".

\section{Fontes:}

» End: https://buff.ly/2HWIOqF

» End: http://www.andifes.org.br/seminario-conjunto-ira-elaborar-contribuicao-das-universidades-publicas-para-educacao-superior-na-america-latina-e-no-caribe-publicacao/

» End: http://www.andifes.org.br/o-financiamento-da-educacao-publica-superior-no-brasil/

\section{Case 3 - Regional- América Latina e Caribe}

Em 28 e 29 de agosto de 2017, o Diretor do Instituto Internacional da Unesco para a Educação Superior na América Latina e Caribe (Unesco Iesalc), Pedro Henríquez Guajardo, e o Coordenador Geral da III CRES, Conferência Regional de Educação Superior, Francisco Tamarit, coordenaram um encontro de Redes regionais. O encontro de RedES, em sua oitava edição, teve abrangência regional e, neste ano, foi escolhida a cidade de Porto Alegre em seu espaço Ufrgs, sala Fahrion, onde vinha se realizando o Ciclo de Conferências em preparação para a III CRES. Foram convidados os líderes de redes de universidades dos países da região, os Conselhos de Reitores e os 
representantes de organismos e agências de cooperação do âmbito regional latinoamericano. Localmente o evento foi apoiado pela Ufrgs, pela PUCRS e pelo Grupo Coimbra de Universidades Brasileiras que também enviaram seus representantes e convidados. No entanto, este foi um evento restrito aos convidados oficiais podendo participar do mesmo apenas alguns observadores, destacados para tal pelos organizadores e grupo de apoiadores. Os eventos RedES são promovidos, organizados e desenvolvidos anualmente pelo Iesalc e realizados em diferentes países. Um encontro desta natureza, segundo o Iesalc, constitui uma plataforma para participação e reflexão sobre a educação superior regional e sub-regional. Seu objetivo é alcançar formas de criar uma articulação estratégica entre os projetos e atividades das redes que tratam da educação superior. O Encontro de RedES realizado em Porto Alegre, visava discutir a educação superior regional de frente aos objetivos do desenvolvimento sustentável, visava analisar, debater e intercambiar ideias sobre a futura estrutura dos temas a serem debatidos na CRES 2018. Pretendeu dialogar com os parceiros sobre a divulgação do evento dos Cem Anos de Reforma de Córdoba e formular uma estratégia, concertada entre os participantes, para o fortalecimento da educação superior na região. A metodologia do encontro foi entendida como participativa pois se estruturou com base em processos dialógicos "interepistêmicos e interdisciplinares" com uma agenda em quatro partes distintas, algumas das quais conduzidas e moderadas pelas organizações convidadas. Na parte inicial do evento duas conferências foram previamente agendadas. A primeira, intitulada Conhecimento e inovação. Desafios para Educação superior foi proferida pela Dra. Rosaura Ruiz Gutierres da Unam e a segunda, Etapas da organização, avanços na construção temática, estratégias de divulgação e participação: os Foros virtuais e o mapa de eventos preparatórios da CRES 2018, foi apresentada a duas mãos por Francisco Tamarit e Pedro Henriques Guajardo. A outra parte do seminário constava de cinco painéis. Em cada painel havia vários apresentadores das temáticas pré-decididas para a CRES, com um coordenador e um relator. Cada painel foi organizado por três ou mais redes. As redes representadas foram: ARIUSA, Aliança das redes de universidades ibero-americanas pela sustentabilidade e meio ambiente; UNAMAZ, Associação das universidades da Amazônia; ANUIES, Associação nacional das universidade e instituições de ensino superior; ANDIFES, Associação nacional dos dirigentes das IES federais,; CINDA, Centro interuniversitário de desenvolvimento; RIACES, Rede ibero-americana de garantia da qualidade no ensino superior; UDUAL, União das universidades da América Latina e do Caribe; CESUCA, Conselho superior universitário Centro-americano; RUIICAY, Rede de universidades indígenas; ASCUN, Associação colombiana de universidades; AUGM, Associação de universidades grupo Montevideo; OUI-IOHE, Organização universitária centro-americana; ABRUEM, Associação brasileira de reitores de universidades estaduais e municipais; RUTyP, Rede de universidades tecnológicas e politécnicas da AL y C; ADRU, Associação dominicana de reitores universitários; CIN, Conselho universitário nacional; ReLARIES, Rede latino-americana de redes de responsáveis de relações internacionais das instituições de ensino superior; AUALCPI, Associação das universidades da AL y C para integração; CRISCOS, Conselho de reitores para a integração da sub-região centro-oeste da América do Sul; REDE ZICOSUR universitário, Zona de integração do centrooeste sul-americano; GRUPO COIMBRA, Grupo Coimbra de universidades; CRUP, Conselho de reitores de universidades privadas; REALCUP, Rede latino-americana e do Caribe de universidades privadas; CES, Conselho de educação superior de Honduras; CONTUA, Confederação dos trabalhadores/as das universidades da América; Rede DEFICIÊNCIA e UNIVERSIDADE, Rede interuniversitária da AL y C sobre deficiência e direitos humanos; ABRUC, Associação brasileira de universidades comunitárias; ODUCAL, Organização das universidades católicas da AL y C; CNU, Conselho nacional das universidades de Nicarágua. Também se fez presente aos debates a OCLAE, Organização continental latino-americana e caribenha dos estudantes. Ao final, terceira parte, realizou-se uma sessão plenária para articulação e posicionamento das redes frente a Terceira Conferência Regional de Educação Superior a realizar-se em 
2018. Também foram indicadas novas redes e iniciativas de articulação entre redes, destacando-se a perspectiva do ENLACES, Espaço latino-americano e caribenho de educação superior, proposta de criação a ser levada à reunião de Córdoba. Um grupo de relatores, previamente indicados, elaborou o relatório final que foi sendo construído à medida que o evento avançava em suas discussões e reflexões e debates. O relatório continha as conclusões dos painéis. A intenção da organização metodológica foi criar insumos para serem apresentados como uma contribuição ao processo de construção dos conteúdos para as sessões temáticas da CRES. Na quarta parte do evento elaborouse um documento sintese, cujo Moderador foi o prof. Dr. Nicolas Bruno Maillard, Secretário de Relações Internacionais da instituição anfitriã. Ao encerramento, leu-se a Declaração do Encontro de RedES de Porto Alegre. Na sessão de conclusão dos trabalhos as intervenções foram de Pedro Henríquez Guajardo, Diretor Unesco-Iesalc, Comitê Executivo da CRES 2018, Evilázio Teixeira, Reitor da PUCRS e Rui Carlos Oppermann, Reitor da Ufrgs. Os resultados e produtos deste encontro foram enviados à organização da CRES 2018.

\section{Fontes:}

» Iesalc Unesco CRES 2018. Agenda preliminar. VIII encontro de Redes universitárias e conselhos de Reitores da América Latina e Caribe: em direção à CRES 2018. A educação superior regional frente aos objetivos de desenvolvimento sustentável. Porto Alegre, Brasil, 28 e 29 agosto de 2017.

» Correio do Povo. Evento reúne dirigentes acadêmicos de 18 países. Ensino. Correio do Povo. Porto Alegre, Terça-feira, 29 de agosto de 2017.

\section{As universidades usam sua inteligência para repensar-se}

Os cases relatados mostram atividades acadêmicas que retomaram os acontecimentos de Córdoba para dar impulso ao repensar-se da universidade sobre si mesma, suas angústias e aflições.

No Case 1, uma iniciativa local estendeu-se de julho de 2017 a abril de 2018, congregando pessoas das mais diversas origens para discutir a universidade com vistas ao seu futuro. O motivo foi a a realização da CRES; o impulso foi o grito reformista dos estudantes de 1918. Os conferencistas abordaram temas da contemporaneidade cujos títulos e endereços foram apresentados acima. Uma análise comparativa entre as distintas realidades dos países da América Latina e do Caribe ${ }^{1}$ pôde ser observada a partir das conferências. Ao encerrar o ciclo de conferências, o curador produziu essa análise e mostrou o posicionamento da educação superior como elemento fundamental para a conquista da cidadania, motor do desenvolvimento humano sustentável e elemento de integração regional e internacional. Identificou um "espírito universitário-acadêmico comum", capaz de agregar e mobilizar as instituições de ensino, as comunidades universitárias e a sociedade (Netto, 2017).

Dentre as muitas perspectivas abordadas pelos conferencistas destacadas do Case 1, salienta-se o entendimento da "educação superior como um bem público forjado por tensões entre tradição acadêmica e novas demandas do desenvolvimento social, econômico, profissional, disciplinar e científico" bem como "as mudanças que vem ocorrendo na expansão da oferta e na diversificação institucional e programática da educação superior e sua articulação com a educação básica". Foi salientado "o poder e a fadiga das políticas de avaliação em larga escala na problemática da qualidade da Educação Superior" (Luce, 2017). "A imbricação entre a concepção de educação, postulada por políticas públicas, e sua materialidade, no tocante à relevância social, à equidade e 
à qualidade da educação", foi destacada (Morosini, 2017). O tema foi abordado na perspectiva de uma região emergente, como a latino-americana e caribenha, na qual a integração, regionalização e internacionalização, devem ser concebidas para além da mobilidade acadêmica sul-norte e numa perspectiva de internacionalização solidária. A diversidade étnico-cultural acolhida pela universidade foi salientada. "Faz pouco mais de duas décadas que a América Latina começou a conhecê-la. A explicação para este reconhecimento tardio é fruto de uma diversidade histórica calcada na escravidão, no extermínio e na exclusão. Ao abordar a diversidade cultural e a interculturalidade na América Latina e no Caribe se faz necessário entender que são conceitos contemporâneos utilizados muitas vezes com sentidos políticos e sociais opostos" (De Deus, 2017). Também a autonomia universitária, a carreira docente, o acesso ao ensino superior, a gratuidade do ensino público e o financiamento da educação foram os temas debatidos nas conferências (Rolim, 2017). A universidade sendo uma instituição com dinamismo próprio está fortemente marcada pela constante renovação de sua comunidade e pelo acúmulo de novo conhecimento a ser incorporado aos currículos dos cursos. $\mathrm{O}$ debate sobre a Pós-graduação e a Pesquisa, atividade com assimétrico desenvolvimento na região, fez emergir a visão estratégica da produção de conhecimento como um fator de desenvolvimento sustentável. A integração entre graduação e pós-graduação, ampliando as oportunidades formativas, em conjunto com a clara definição de agendas de pesquisa científica socialmente relevantes e programas de apoio à ciência com recursos financeiros, públicos e privados, suficientes e estáveis, foram entendidos como fundamentais (Amaral, 2017)

Ainda no Case 1, as conferências trouxeram um convite ao público para pensar as transgressões de Córdoba. Resgatou-se o contexto histórico das universidades latinas e o movimento dos estudantes de 1918 destacando-se a preparação político e pedagógica dos jovens cordobeses. Foi levantada a hipótese da existência de uma Pedagogia da Reforma que ensinou a transgressão e a crítica; que forjou um novo modelo de universidade, comprometida com a sociedade, com liberdade de cátedra e co-gestionada. As transgressões de Córdoba se refletiram na conformação de um modelo de universidade crítica latino-americana. A consciência social e a coragem dos estudantes argentinos de 1918 promoveram uma ruptura que extrapolou o local, tendo reflexos em outros países. Foi lembrado que no Brasil, a força estudantil se evidenciou em momentos importantes da vida nacional, principalmente nos anos 1960 na luta contra a ditadura e, nos anos 1980, no movimento Diretas Já (Leite, 2017, 2018).

No case nacional, Case 2, em Brasília, os temas candentes foram o financiamento da instituição pública versus a mercantilização das instituições privadas em busca de lucros que incluem recursos governamentais. A crítica e o debate entre membros de associações de dirigentes universitários foram relevantes para firmar posições de luta na reversão de uma situação de financiamento que se mostra caótica em relação ao futuro. A reunião nacional também firmou posição com relação à integração regional latino-americana, a qual objetiva a formação e a pesquisa com vistas a diminuir as assimetrias existentes entre os sistemas educacionais dos países da região.

No Case 3, o case regional, evidenciou-se uma dinâmica condutora de preparação objetiva para a III CRES e uma definição pela criação do ENLACES. No evento de Redes de Educação Superior e o Conselho de Reitores, sob o comando Iesalc Unesco, participaram 18 países e várias Redes, com intervenção de uma organização estudantil. As discussões foram metodologicamente organizadas para resultar em um documento síntese. Salienta-se que o discurso inicial sobre conhecimento e inovação mostrou uma América Latina em procura de um futuro com democracia e justiça social para o qual se questionou o sentido de ter uma universidade igual à do medievo europeu. $\mathrm{Na}$ contemporaneidade a universidade lida com o conhecimento científico, profissional e 
pedagógico criando alternativas para um mundo em movimento. Fazer a autocrítica e protagonizar a busca de soluções é o imperativo. A busca de conhecimento deve ser fomentada nas universidades latino-americanas e caribenhas na perspectiva de dimensão social de seu alcance, com preocupação ambiental e objetivando produzir inovações que beneficiem aos povos. Com esta preocupação, as redes de universidades discutiram seus novos papéis nas sociedades da região buscando expansão com qualidade, abertura à interculturalidade, fortalecimento da investigação, extensão e ensino. Do conjunto dos discursos proferidos depreende-se que este grupo de atores entende a expansão com qualidade o que significa renovação e reforma; currículos flexíveis e ensino voltado ao desenvolvimento integral do aluno, especialmente voltado ao desenvolvimento de valores e ética, considerando a crise moral pela qual as sociedades se estão pautando. Nas discussões foi reiterado que a educação superior oferecida pelas universidades é projeto de toda a vida e não um bem descartável. Este o sentido da universidade como bem social.

Em síntese, o movimento das comunidades universitárias, registrado nos três cases, sob o crivo da reforma educativa estudantil do 1918, expandiu-se da esfera local, para a esfera nacional e desta para o âmbito regional latino-americano e caribenho, antes do evento da CRES. A inspiração foi Córdoba, o foco foi pensar e repensar a universidade. Mobilizou-se o espírito universitário-acadêmico comum.

\section{O alcance reformista da mobilização de inteligências}

Quando a história faz o apelo, a universidade se repensa. Os casos relatados demonstram a força da pedagogia de Córdoba que transcendeu o século para animar o debate sobre a universidade latino-americana e caribenha. Debate este rigorosamente planejado e realizado atingindo públicos diferenciados em número e em agregação acadêmica. O olhar, talvez cético de Mulgan, diria que foram apenas palavras... "O mundo está testemunhando uma série de revoluções extraordinárias em como o pensamento acontece. Algumas são muito visíveis - como a disseminação da inteligência artificial

2. A crítica poderia apontar que não se questionaram as perseguições que docentes e estudantes universitários vêm sofrendo em alguns países da América Latina. No entanto, esta grave situação, bem como, os problemas pelos quais passam as universidades indígenas, mais os problemas de acesso do estudante negro, indígena, quilombola, transexuais e outros grupos discriminados, foram veiculados nos discursos. Em Conferências Ufrgs, de diferentes modos e alcances, citamos "Movimento estudantil nas universidades brasileiras" (<https:// www.ufrgs.br/cres2018ufrgs/repositorio>, Edilson Nabarro e outro) e "A diversidade cultural e a interculturalidade na educação superior" (< https://www.ufrgs.br/cres2018ufrgs/ repositorio>, Sandra de Deus) que trataram de tais temas. Os discursos mostraram que a politização dos movimentos estudantis, visível na luta contra as ditaduras, vêm cedendo espaço ao ativismo do movimento negro e outros movimentos pela diversidade, as novas pautas do século XXI. Conquanto importante, este artigo não teve o objetivo de fazer a análise dos discursos ou especificar seus conteúdos. A descrição dos Cases, apresentada neste artigo, traz os endereços para acessar cada conembutida em carros, telefones e equipamentos domésticos, e a previsão de tudo, desde reincidência de prisioneiros até resultados de doenças. Algumas são menos visíveis - como o aproveitamento de milhões de mentes em projetos como a Wikipedia ou a ciência cidadã. As universidades devem estar no centro dessas revoluções. No entanto, muitas vezes, permanecem inquietas na periferia" (Mulgan, 2018, s/p). A crítica aponta o conservadorismo institucional e as modas passageiras. Nesse sentido estaríamos produzindo pensamento apenas porque Córdoba existiu. Estaríamos vivendo um momento, uma passagem, um apelo da história!

A autocrítica poderia levar-nos a submergir nos acontecimentos e repetir que foram apenas palavras em muitas conferências e seminários e reuniões, nas quais houve reduzida participação estudantil ${ }^{2}$. Ou, poderíamos dizer que não estamos no centro das daquelas revoluções, que estamos na periferia delas, a reboque. Contudo, estamos no centro de outras revoluções impulsionadas pelo viver em códigos de injustiça social e crises de valores éticos, políticos, morais e sociais. O pensamento nesta parte do mundo tem que voltar-se, sim, para a ciência cidadã, envolver as mentes, com projetos de inovação, empreendedorismo, inteligência artificial e outros tantos, mas, há que preocupar-se profundamente com a formação dos diferentes públicos da universidade.

Permanecem válidos os ensinamentos de Pedro Krotsch sobre as novas tramas de sentidos que se quer dar à universidade, na qual o espaço público cede lugar para a instituição empresa, em detrimento da pedagogia reformista: 


\begin{abstract}
A reforma como ideia de universidade ilustrada e comprometida foi objeto de ataques permanentes na última década. Durante a qual se tentou substituir a concepção de espaço público no qual se elaboram identidades e sentidos, por uma concepção de universidade como empresa. O romantismo, o arielismo e o latinoamericanismo, o caráter juvenil e geracional, a ideia de vanguarda intelectual daquele movimento de Reforma parecem incompatíveis com esta nova trama de sentidos que confluem em torno ao critério de eficiência e utilidade das instituições e carreiras individuais, da prevalência de valores expressivos nos jovens, da emergência de novas formas de construir a identidade e a solidariedade. (Krotsch, 2004, p. 103)
\end{abstract}

A descrição e a análise dos acontecimentos mostrados nos Cases trazem a diferença do pensamento latino-americano em relação ao pensamento eurocêntrico manifestado e criticado por Krotsch. Nesta parte do mundo, as instituições fecham por falta de recursos, os laboratórios descontinuam suas pesquisas por falta de insumos, as instituições são confrontadas por empreendedores de mercado que tomam os fundos públicos para seu próprio lucro, os dirigentes das instituições têm limitado acesso à definição das políticas públicas que afetam suas ações e a governança das universidades. As instituições públicas, portanto, encontram forças ao reunir-se; ao colocarem as inteligências em contato através das palavras proferidas; ao tomarem a Reforma de Córdoba em seu sentido de autonomia como base para o desenvolvimento da ciência e da cultura. Fruto da investigação e do planejamento dos temas, o capital que as inteligências produziram resultou em conhecimentos que extravasaram em palavras e destas em textos e destes em ações.

O Manifesto Liminar (Barros, 1918) refletiu uma pedagogia, reformista e duradoura no século, centrada em preocupações relacionadas à organização e governo da universidade, à reforma do ensino e suas metodologias, à projeção política e social da universidade na sociedade e à integração regional latino-americana. Todas essas pautas, e outras, se fizeram verdade no movimento levado a efeito e relatado nos três Cases. As palavras proferidas, os documentos elaborados, as pautas levadas à CRES foram apenas o produto visível. Por dentro, assomou a periodicidade revolucionária e a criatividade universitária em toda sua profundidade mexendo com valores e mitos, revolvendo angústias e medos, armando forças para o bom combate.

Quando a história faz o apelo, a universidade se diz presente. Quando as inteligências são convocadas, a palavra e as vozes são ouvidas e ressoam na América. No momento histórico este é o alcance reformista possível. A preparação para a CRES foi a motivação. Quando a história faz seu apelo, a universidade pensa e se repensa. Como concluem Netto et al:

O momento histórico de crises e de transformações da sociedade contemporânea traz a oportunidade ímpar de repensar a educação superior e o ideal universitário. Esta é justamente a força da universidade do futuro: a esperança na construção de um mundo melhor. Pensar um novo modelo para a universidade latinoamericana e caribenha contribuirá, indubitavelmente, para a união de nações tão próximas quanto símiles em dificuldades e riquezas. (Netto et al., 2018, p.27) 


\section{Q Referencias bibliográficas}

"Amaral, L. (2017). Pós-graduação e ciência na AL. Trabajo presentado en Conferências CRES 2017. Ufrgs. Porto Alegre, RS, Brasil. São vídeos.. Recuperado de: https://www.ufrgs.br/cres2018ufrgs/repositorio.

» Barros, E. F., Bordabehére, I. C., Valdés, H., Sayago, G., Castellanos, A., Méndez, L. M., Bazante, J. L., Maceda, C. G., Molina, J., Pinto, C. S., Biagosch, E. R., Nigro, A. J., Saibene, N. J., Allende, A. M., \& Garzón, E. (1918 junio). La Juventud Argentina de Córdoba a los Hombres Libres de Sudamérica (Manifesto Liminar) La Gaceta Universitaria, Órgano de la Federación Universitaria de Córdoba, n1o.

»De Deus, S. (2017). Educação superior, diversidade cultural e interculturalidade na AL e C. Conferências CRES 2017. Recuperado de: https://www.ufrgs.br/ cres2018ufrgs/repositorio.

»Krotsch, P. (2004). Los estudiantes universitarios como actores de reformas en América Latina: la cultura de los jóvenes y la crisis de la institución. Avaliação. Revista da Rede de Avaliação Institucional da Educação Superior, 9(4), 99-119.

»Leite, D. (2017). A pedagogia da Reforma de Córdoba e a integração regional na AL e Caribe. Conferências CRES 2017. Recuperado de: https://www.ufrgs.br/ cres2018ufrgs/repositorio

»_. (2018). A Pedagogia da Reforma de Córdoba. Integración y conocimiento. ${ }_{1}$ Córdoba, Argentina. Vol(8) 7, Num.1 . Recuperado de:Em: https://revistas. unc.edu.ar/index.php/integracionyconocimiento/article/view/20103/20088

»Luce, M. B. (2017). A educação superior como parte do sistema educacional na AL e C. Conferências CRES 2017. Recuperado de: https://www.ufrgs.br/ cres2018ufrgs/repositorio.

" Morosini, M. (2017). Direito à educação superior na AL e C. Conferências CRES 2017. Recuperado de: https://www.ufrgs.br/cres2018ufrgs/repositorio

"Mulgan, G. (2018). Why are universities not leading the charge for better thinking? The World University Rankings. Recuperado de: https://www. timeshighereducation.com/opinion/why-are-universities-not-leading-chargebetter-thinking

» Netto, C. A. (2018). Cem Anos da Reforma de Córdoba - Um Novo Manifesto? Trabajo presentado en Conferências CRES 2017. Recuperado de: https://www. ufrgs.br/cres2018ufrgs/repositorio

» Netto, C. A., Leite, D., Tutikian, J.F., Tavares dos Santos, J. V., Luce, M. B., Morosini, M., De Deus, S., \& Panizzi, W. (2018). Repensando a educação superior na América Latina e Caribe: Princípios, missão e valores. In P. H. Guajardo (Coord), El papel estratégico de la educación superior en el desarrollo sostenible de América Latina y el Caribe (pp.17-30). Caracas, Venezuela: Unesco/lesalc, Córdoba, Argentina: Editorial Universidad Nacional de Córdoba. Recuperado de: http:// grupomontevideo.org/sitio/wp-ontent/uploads/2016/o9/LibroAUGM25.pdf

" Ribeiro, D. (1982). A universidade necessária. 4a ed. Rio de Janeiro, Brasil: Paz e Terra.

»_. (1983). O dilema da América Latina. Estruturas de poder e forças insurgentes. za ed. Petrópolis, Brasil: Vozes. 
» Rolim, E. (2017). A comunidade universitária e a educação superior na AL e C. Conferências CRES 2017. Recuperado de: https://www.ufrgs.br/cres2018ufrgs/ repositorio.

\section{Bibliografía de consulta}

"Amaral, N. C. (2018, Abril 25). O financiamento da educação pública superior no Brasil. Andifes. Recuperado de: http://www.andifes.org.br/o-financiamento-daeducacao-publica-superior-no-brasil/

"Andifes. (2018, abril 19). Seminário conjunto irá elaborar contribuição das universidades públicas para Educação Superior na América Latina e Caribe. Recuperado de: http://www.andifes.org.br/seminario-conjunto-ira-elaborarcontribuicao-das-universidades-publicas-para-educacao-superior-naamerica-latina-e-no-caribe-publicacao/

»Evento reúne dirigentes acadêmicos de 18 países (19 de agosto de 2017). Correio do Povo, Ensino, p.16.

» llea/UFRGS, Adufrgs Sindical (2018, Abril 12). Atualidade da Reforma Universitária de Córdoba. Ciclo de debates. A Universidade do Futuro. Recuperado de: www.adufrgs.org.br/noticias/53449/

» Unesco/lesalc CRES 2018 (28 e 29 agosto de 2017). VIII encontro de Redes universitárias e conselhos de Reitores da América Latina e Caribe: em direção à CRES 2018. A educação superior regional frente aos objetivos de desenvolvimento sustentável. Agenda preliminar. Folder. Porto Alegre, Brasil.

»Unesco/lesalc (23 de abril de 2018). Seminario conjunto elaborará contribución de las universidades públicas para la Educación Superior en América Latina y el Caribe. Recuperado de: https://buff.ly/2HWIOqF

\section{Carlos Alexandre Netto}

Graduado em Medicina, com mestrado e doutorado em Bioquímica pela Universidade Federal do Rio Grande do Sul. Professor titular de Bioquímica, pesquisador 1 A CNPq, Conselho Nacional de Desenvolvimento Científico e Tecnológico de Brasil. Foi reitor da UFRGS por dois mandatos, entre 2008 e 2016. Correo electrónico: netto@gabinete. ufrgs.br

\section{Denise Balarine Cavalheiro Leite}

Doutora em Ciências Humanas pela Universidade Federal do Rio Grande do Sul (Ufrgs), professora titular Departamento Ensino e Currículo aposentada. Docente permanente Programa de Pós-Graduação em Educação, Faculdade de Educação da Universidade Federal do Rio Grande do Sul (Faced/Ufrgs) e pesquisadora, nível $1 \mathrm{~A}$ do $\mathrm{CNPq}$, Conselho Nacional de Desenvolvimento Científico e Tecnológico de Brasil. Correo electrónico: denise.leite@hotmail.com.br 
